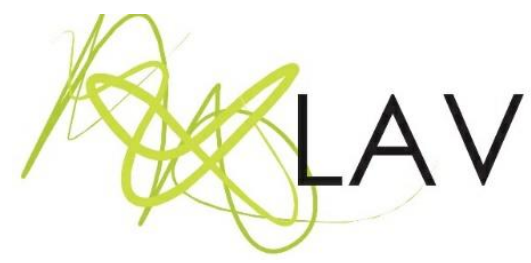

\title{
Flores Raras: lesbianidades e as espacialidades de armários e heterotopias
}

'Reaching for the Moon': lesbianity and the spatiality of closets and heterotopias

\author{
Alessandro Garcia Paulinoi \\ Universidade Federal de Lavras \\ Cláudia Maria Ribeiroii \\ Universidade Federal de Lavras \\ Nilson Fernandes Dinisiii \\ Universidade Federal de São Carlos
}

\begin{abstract}
Resumo
Neste artigo, discute-se sobre as lesbianidades e o cinema, imbricando conceitos do 'imaginário de águas', 'armário' e 'heterotopias'. Esta escrita tem como objetivo analisar o encontro entre o cinema e o campo das sexualidades a partir de três recortes de cenas do filme Flores Raras (2013), sob direção de Bruno Barreto. Entende-se o cinema como um inventor de uma pedagogia do olhar, de uma cultura visual, que faz emergir subjetividades e modos de existência a partir de seus modos de endereçamento. A análise das imagens (cenas) foi realizada a partir de sua visualização, bem como do entrecruzamento com o referencial teórico. Por fim, a história de Flores Raras (2013) demonstrou-se envolvente e passível de problematizações e análises, levando em consideração o amor entre mulheres, a água, as espacialidades e as geografias dos corpos presentes nas imagens.
\end{abstract}

Palavras-chave: Cinema, sexualidades, espaços heterotópicos.

\begin{abstract}
In this article, we intend to discuss lesbianity and movie theater, interweaving concepts from the 'imaginary of waters', 'closets' and 'heterotopias'. This writing has an objective to analyze the encounter between movie theater and the field of sexualities based on three clippings from scenes in the movie Reaching for the Moon (2013), direction by Bruno Barreto. In this case, we understand movie theater as an inventor of a pedagogy of look, the visual culture, which reveals subjectivities and modes of existence from its addressing ways. The analysis of the images was based on the scenes visualization as well as from the intersection with the theoretical framework. Finally, the story of Reaching for the Moon (2013) proved to be engaging and the subject of problematization and analysis taking into account the love between women, 'the water', the spatialities and the geographies of the bodies present in the images.
\end{abstract}

Keywords: Movie theater, sexualities, heterotopic spaces. 


\section{As possibilidades para problematizações em Flores Raras}

Mergulhamos no campo da cultura visual, entretecendo as lesbianidades, o imaginário das águas, os conceitos de heterotopia e do armário. O encontro entre o cinema e o campo da educação, no qual consideramos o cinema como pedagogia, remete-nos às palavras de Migliorin e Barroso (2016), de como o cinema inventa uma pedagogia. As imagens fazem emergir subjetividades e modos de existência. O convite é para compartilharmos conhecimentos a partir do filme Flores Raras (2013).

Nossa intenção não é descrever incansavelmente todos os trechos que seguem a composição da narrativa, mas sim buscar recortes, intencionalmente, para efetivar as problematizações.

Apresentamos uma breve ficha técnica de Flores Raras (2013). Com título em inglês de Reaching for the moon, tem duração de 118 minutos, possuindo em seu elenco Glória Pires (interpretando Lota de Macedo Soares), Miranda Otto (Elizabeth Bishop) e Tracy Middendorf (Mary), com direção de Bruno Barreto e coprodução da Globo Filmes e LC Barreto.

A sinopse retirada da Globo Filmes ${ }^{1}$ nos conta a história de amor entre Elizabeth Bishop², poeta americana vencedora do Prêmio Pulitzer em 1956, e Lota de Macedo Soares, arquiteta carioca que idealizou e supervisionou a construção do Parque do Flamengo, no Rio de Janeiro. A tensão dessa história de amor se passa mediante as adversidades conflituosas, como o recém-término de Lota com Mary, bem como a vivência das possibilidades afetivas para aquela época. Ambientado no Brasil dos anos 50 e 60, quando a Bossa Nova explodia e Brasília era construída e inaugurada, o longa acompanha a história dessas duas grandes mulheres e suas trajetórias.

Mediante a breve sinopse, instigamos o/a leitor/a para que se inteire da obra completa, visto que não nos interessa neste artigo explorar todas as cenas que compõem os 118 minutos de filme. A obra está disponível nas plataformas de streaming e é de fácil acesso para visualização. Outro ponto a ser levantado é que foi necessária a visualização do filme por diversas vezes de modo a elencar recortes que pudessem se constituir em um corpo empírico para a problematização e discussão do cinema lésbico brasileiro e do que se tem produzido sobre ele.

\footnotetext{
${ }^{1}$ Disponível em: <http://globofilmes.globo.com/filme/floresraras/>. Acesso em: 10 abr. 2020. É importante ressaltar que essa sinopse foi retirada do site oficial de produção e distribuição do filme.

2 É marcante situar o contexto poético nas obras de Bishop. Segundo Anastácio (2002, p. 65), "analisando a trajetória intersemiótica embutida nos manuscritos de Bishop, percebe-se como vão se processando transmutações de estímulos diversos, notadamente de ordem visual, mas também sonora, em signos verbais. Destaca-se, então, o caráter condensador, sintético da poesia de Bishop, traço que a imagem poética é capaz de registrar e guardar, a partir de sua percepção transformadora. Tal percepção dá margem na escrita de Bishop a um discurso especialmente rico em metáforas, símiles, símbolos, metonímias, à medida que a autora vai transformando as suas percepções poéticas, inclusive os próprios espaços geográficos, em poesia".
} 
Portanto, nos próximos parágrafos, colocamo-nos na tentativa de construir um mosaico dessas cenas fragmentadas para que possamos entender de que modo esse cinema tem nos subjetivado e as inúmeras formas simbólicas que nos endereçam quando estamos frente a frente com o filme e, a partir disso, buscar um enlace teórico no intuito de entrecruzar as teorias propostas por este artigo frente às imagens.

\section{Cena: A viagem ${ }^{3}$}

A cena inicial do filme apresenta um barco nas águas de um lago, símbolo de viagem, de travessia e de passagem. "Nos textos mitológicos ele é o símbolo e o meio de passagem para o outro mundo". Em seguida, a personagem que vivia nos Estados Unidos decide buscar outras paragens e embarca em um navio para o Brasil (Figura 1). Chevalier e Gheerbrant (1998) afirmam que "a vida presente também é uma navegação perigosa. Desse ponto de vista, a imagem da barca é um símbolo de segurança. Favorece a travessia da existência" (CHEVALIER e GHEERBRANT, 1998, p. 121, 122). Bishop, no navio que a levava ao Brasil - como se não bastasse o anúncio de muitas mudanças, em uma das cenas, uma lua cheia refletida no mar aparece para anunciar as transformações - qual a simbologia da lua? Esses autores dizem que ela representa a periodicidade e a renovação. É o símbolo dos ritmos biológicos, pois é um astro que "cresce, decresce e desaparece, cuja vida depende da lei universal do vir-a-ser, do nascimento e da morte" (ibidem, p. 561).

Flores Raras anunciava o movimento de suas personagens - um eterno retorno aos ritmos da vida, iniciado pela viagem de Bishop em direção ao Brasil. Além da simbologia do barco e da lua, a força da simbologia do mar: "Símbolo da dinâmica da vida. Tudo sai do mar e tudo retorna a ele: lugar dos nascimentos, das transformações e dos renascimentos. Águas em movimento" (ibidem, p. 592). A viagem de Bishop estava repleta de incertezas do que encontraria. $E$, encharcando as cenas do filme, o imaginário das águas.

Nesse imaginário, a água brota como um símbolo de contradições. Pensá-la para além das oposições, problematizando as cenas do filme, faz-nos mergulhar em muitas perguntas: a água é cúmplice das transformações da relação dos seres humanos com o seu corpo? A água inspira o aprendizado erótico do corpo? A sensualidade é estimulada pelo contato com a água? Os sentidos afloram no contato com a água? Água e transgressão são possibilidades no exercício dos prazeres? A água fomenta pensamentos

\footnotetext{
${ }^{3}$ É válido ressaltar que os nomes para as cenas foram designados por nós no intuito de simbolizar e concretizar o entorno da narrativa produzida pelo filme.
} 
eróticos, fantasias, borbulhando nos mitos, nas lendas, nas artes? O imaginário das águas borbulha no enredo do filme Flores Raras.

Aqui, faz-se necessário, apresentar o conceito de imaginário. Monique Augras (2009, p. 10) potencializa o conceito, não como fuga da realidade, mas algo que a integra, pois o imaginário é uma construção: "O estudo sistemático das produções do imaginário efetivo propicia o acesso a aspectos mais profundos dessa realidade, disfarçados pela roupagem colorida do fantástico". Também Gilbert Durand (1997, p. 221), discípulo de Bachelard, faz da temática do imaginário, desde seu livro As estruturas antropológicas do imaginário, escrito em 1960, "uma confluência unificadora de todas as ciências humanas e sociais". O autor define o imaginário como capital antropológico. Esta definição "possibilita estabelecer o diálogo entre as diversas ciências do homem (e acrescentamos, da mulher). Não mais antagonismo entre razão e imaginação, que são, ambas, ferramentas na construção do mundo" (ibidem, p. 222).

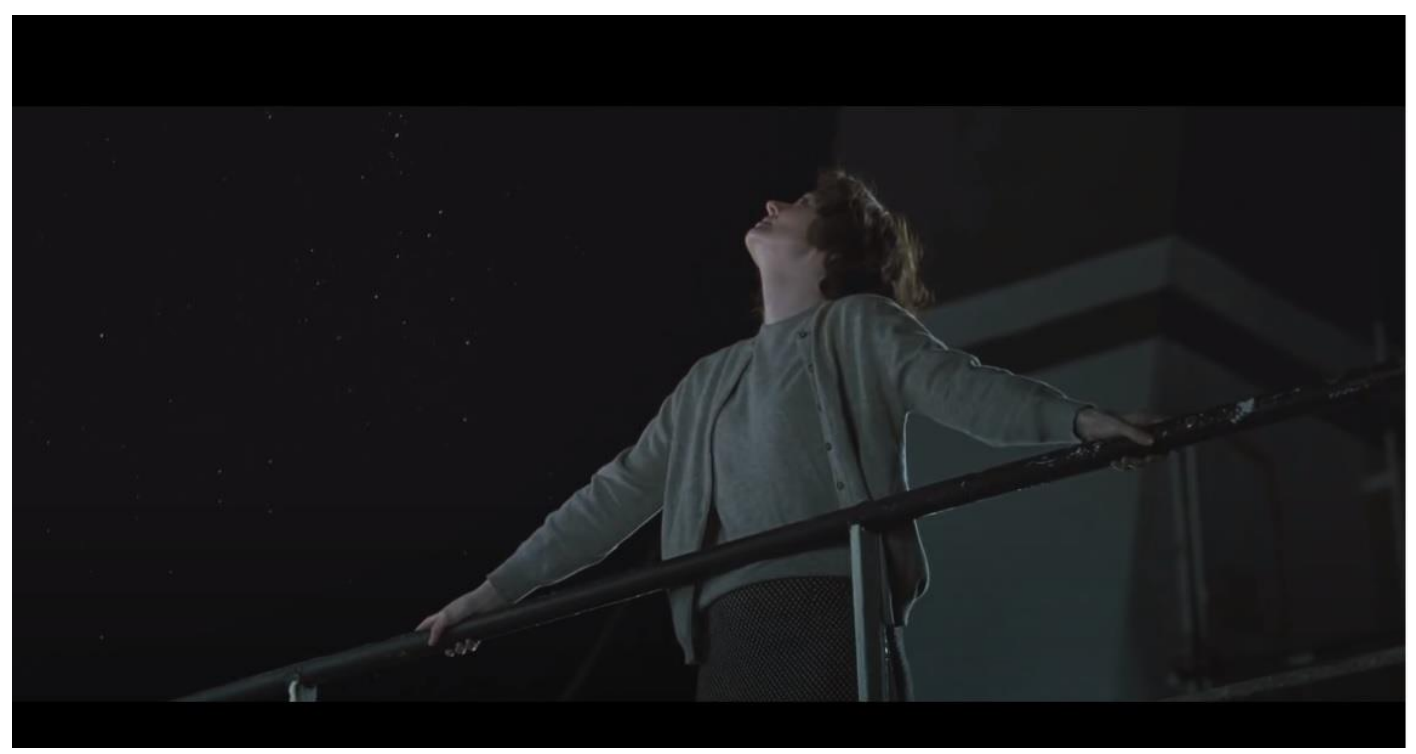

Figura 1: Bishop e a viagem

Fonte: Flores Raras, 2013.

\section{Cena: Chegada ao Brasil}

Elizabeth Bishop desembarca do navio que viera dos Estados Unidos, buscando a denominada "Cura Geográfica"4. A cena seguinte mostra a personagem ao fundo caminhando e desembarcando com outros passageiros. Ela porta uma vestimenta clássica, e uma música instrumental ao fundo acompanha seus passos rumo à

\footnotetext{
${ }^{4}$ A temática da cura geográfica é ponto central na perspectiva de vida de Bishop, principalmente pelo fato de que a transitoriedade entre lugares e regiões, ou seja, sair dos Estados Unidos e vir para o Brasil, poderia significar essa cura. Pereira (2015), apoiado em Britto (1995), relata-nos essa perspectiva mediante a tradução de um poema de Elizabeth Bishop: "Ah, turista,/ Então é isso que este país tão longe ao sul/ Tem a oferecer a quem procura nada menos/ Que um mundo diferente, uma vida melhor?".
} 
conferência dos documentos e passaporte para a entrada no Brasil. Elizabeth observa ao seu redor, e ao fundo vemos uma moça em uma escada limpando um relógio central; Bishop observa atentamente a personagem que, mesmo no topo de uma escada, usa uma saia. Bishop fica a reparar de baixo para cima com um semblante de curiosidade. A cena é interrompida com a chegada de Lota e Mary que vão ao encontro de Elizabeth. As saudações assustam Elizabeth pelo contato, pelo abraço e pelo beijo no rosto.

É importante ressaltar que, na cena do encontro, vemos uma Lota diferente de Mary e Bishop, no que diz respeito à vestimenta, à personalidade e no modo como dirige euforicamente seu carro, como aponta Mary. Esses aspectos evidenciam as construções das diferenças sobre as personagens envolvidas. De um lado, muita intensidade e, no outro, leveza, delicadeza e timidez.

O caminho percorrido leva à Samambaia, na zona rural do Rio de Janeiro, onde Lota vive com Mary, longe dos olhares da capital. O local, como discutiremos, funciona tanto como um 'armário', como um espaço heterotópico. Novamente, os contrastes entre as nacionalidades surgem, principalmente na perspectiva afetiva, quando Bishop é apresentada aos outros sujeitos que ocupam aquele local.

Nos minutos finais dessa cena, percebemos que Bishop observa Lota de forma a analisar suas posturas, seu dialeto, sua interação com os outros homens que trabalham em Samambaia (Figura 2). Lota sobe no trator, beija o rosto de seus funcionários e dialoga sobre a construção de uma nova casa; Bishop aprecia e acha diferente. Mary logo comenta o quanto Samambaia é diferente de $\operatorname{Vassar}^{5}$ e Bishop concorda.

Nas cenas posteriores, vemos Mary proferir que ali podem vivenciar sua experiência, seus desejos e suas sexualidades. Temos um curto diálogo entre Mary e Bishop que exalta essa concepção:

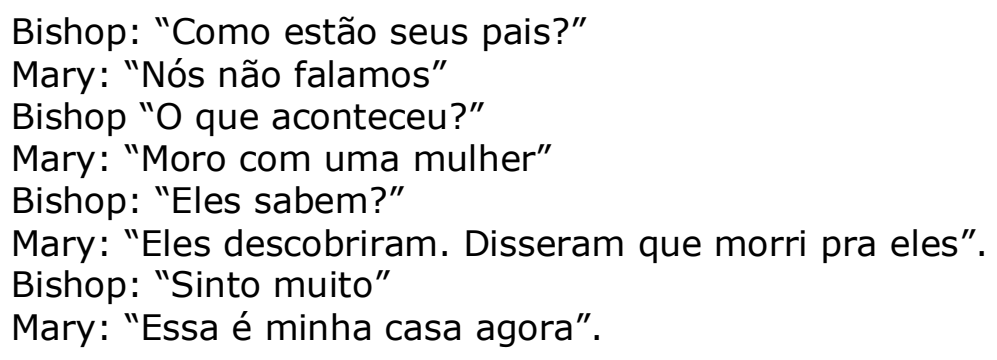

A partir desses aspectos, propomos uma discussão sobre a temática das espacialidades, no que tange as teorias sobre o armário e a heterotopia ou de como entendemos Samambaia e suas relações com as sexualidades.

\footnotetext{
5 Vassar, ou melhor, Vassar College, é um colégio renomado de ensino e de artes nos Estados Unidos, localizado em Poughkeepsie. O trocadilho feito provavelmente remete aos modos e processos de comunicação e afetividade entre os sujeitos que ocupam os lugares, no caso Vassar e Samambaia.
} 


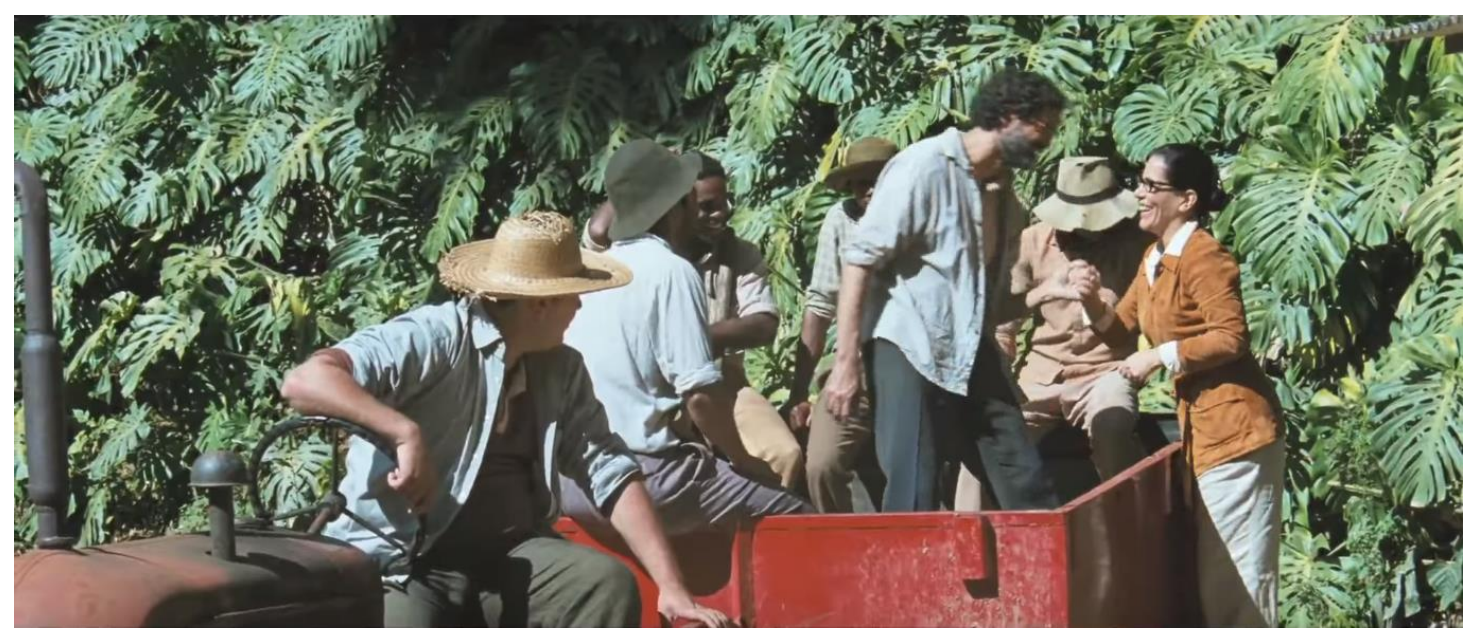

Figura 2: Lota e Samambaia Fonte: Flores Raras, 2013.

\section{Armário, heterotopia ou como concebemos Samambaia}

O que pretendemos investigar objetiva-se na possibilidade de alinhar a cena delineada (recorte) com o referencial teórico, sem abster obviamente dos processos subjetivos e do modo de endereçamento ${ }^{6}$, que recaem sobre nós, mediante a visualização das imagens do filme Flores Raras.

O primeiro ponto está diretamente ligado às questões da espacialidade ou de como os locais enfatizados na trama dão sentido à existência dos corpos das personagens; dizemos isso em um paralelo entre Samambaia e a capital do Rio de Janeiro. Samambaia é o principal espaço de constituição de uma construção das diferenças ou até mesmo de adequação a determinadas normas entre os sujeitos que ali ocupam esse espaço. É nesse local em que são proferidas narrativas, nas quais ápices de resoluções de trama são realizados, ou como os corpos são livres para vivenciarem suas experiências, longe dos olhares dos/as outros/as, longe da cidade.

Portanto, um primeiro cruzamento teórico que buscamos é entender Samambaia como um armário. Compreendemos, nesse caso, a palavra armário como um aporte teórico advindo das problematizações, principalmente de Eve Kosofsky Sedgwick (2007), em sua obra denominada Epistemologia do Armário, publicada nos cadernos Pagu por meio do Dossiê Sexualidades Disparatadas. Vemos que grande parte do filme se passa em Samambaia, espaço privado, onde há a possibilidade de que as personagens possam se vincular de modo afetivo sem as amarras de um dito meio social, ou no caso, de como

\footnotetext{
${ }^{6}$ Segundo Ellsworth (2001, p. 11-12), "o modo de endereçamento é um termo dos estudos de cinema, um termo que tem um enorme peso teórico e político. Ele se resume: quem este filme pensa que você é?". De uma forma geral, "os teóricos do cinema desenvolveram a noção de modo de endereçamento para lidar, de uma forma que fosse específica ao cinema, com algumas das grandes questões que atravessam os estudos de cinema, a crítica de arte e de literatura, a sociologia, a antropologia, a história e a educação".
} 
a cidade, e, nesse caso o espaço público, seja sinônimo de heterossexualidade. Essa perspectiva se situa nas discussões realizadas por Preciado $(2017)^{7}$ sobre a questão da topofobia, ou seja, o rechaçamento, o medo do lugar físico, ou medo da presença.

Segundo Sedgwick (2007) apud Miskolci (2013, p. 302), o armário se constitui como:

um regime de controle da sexualidade que rege e mantém a divisão binária hetero-homo da sociedade ocidental desde fins do século XIX. O armário se caracteriza por um conjunto de normas nem sempre explícitas, mas rigidamente instituídas que faz do espaço público sinônimo de heterossexualidade, relegando ao privado as relações entre pessoas do mesmo sexo.

Entendemos Samambaia como um local possibilitador de vivências de prazer ou de ódio, de desavenças e resoluções, de paradoxos e complexidades. Nesse espaço do privado, o armário opera no sentido da possibilidade da visibilidade de uma lesbianidade explícita, o que difere das cenas onde as personagens se encontram na capital do Rio de Janeiro.

Ainda revisitando outros campos teóricos antes de adentrar realmente a obra de Sedgwick, optamos por desvencilhar alguns comentários realizados por Miskolci (2007), na leitura da obra Epistemologia do armário. O intuito continua no entendimento da questão da espacialidade na vida de Lota, Bishop e Mary e de como esses processos vão constituindo o mergulho em suas lesbianidades. De fato, nesse ponto, atentamos para algumas reflexões sobre o contexto social, ou de acordo com Miskolci (2007), de como nossa sociedade ou a modernidade distingue as vidas sentimentais dos sujeitos como as enunciáveis ou aquelas que vivem calcadas no silêncio e até desmaterializadas em sua própria existência.

Seria Samambaia o local, portanto, o espaço calcado nesse silêncio? Nesse sentido, entendemos o silêncio de Samambaia como espaço de possibilidade de suas vivências amorosas, mas, ao mesmo tempo, não enunciáveis no espaço público, porque o local ainda está inserido no espaço do privado, na interpessoalidade e na geografia restrita. Nas cenas iniciais, vemos Mary proferir que ali podem vivenciar sua experiência.

A cena continua com a frase de Mary: "Somos discretas no Rio, mas ninguém nos incomoda aqui. Acho que está além de sua imaginação". O sentimento de pertencimento à localidade confere uma produção de liberdade e de momentos de afetividades

\footnotetext{
7 José Miguel Cortés (2006, p. 162-163), citado por Preciado (2017, p. 6), comenta: 'á lésbicas, mais do que se concentrar num território determinado (ainda que ocasionalmente isso ocorra), tendem a estabelecer redes mais interpessoais. Quer dizer, elas não alcançam uma base geográfica tão clara na cidade e ocupam espaços mais interiores e íntimos, o que as priva - em grande proporção - de ter uma organização política tão evidente e nítida como acontece com os gays. Enquanto a figura do gay aparece como um 'flâneur perverso' (retomando a feliz expressão de Aaron Betsky), a lésbica se vê desmaterializada de modo que a sua inserção no espaço é fantasmática, ela tem a qualidade de uma sombra, tem uma condição transparente ou produz um efeito antirreflexo do vampiro".
} 
inigualáveis. Nesse sentido, o dispositivo do armário opera sutilmente na vida das personagens, como relata Mary: "mesmo que meus pais não me aceitem, essa é a minha casa; vivo distante dos olhos do julgamento e do poder exercido sobre minha sexualidade pela sociedade".

A chegada de Bishop, sua colega na Universidade nos Estados Unidos, mudou completamente seu relacionamento com Lota. Bishop e Lota se apaixonaram. O primeiro beijo foi sob a luz do luar - novamente a lua anunciando as mudanças nos ritmos. $O$ título do filme em inglês é: Reaching for de moon - naquele momento alcançavam a lua! "A lua rege a renovação periódica, tanto no plano cósmico como no plano terrestre, vegetal, animal e humano" (CHEVALIER e GHEERBRANT, 1998, p. 562). Outro relacionamento brotava sob a luz do luar, início das expressões de prazer em um espaço heterotópico - o armário denominado Samambaia.

Assim, retomamos o armário. Em decorrência das contribuições de Sedgwick, é necessário entendermos que o projeto da autora se dá mediante a obra História da Sexualidade I: a vontade de saber, de Foucault (1988), no tocante às contribuições do entendimento, ou na busca dele, da sexualidade como um dispositivo histórico do poder, pensando principalmente nas formas de regulação da vida no sentido social e individual. Nesse sentido, a obra vem contribuir com essa escrita para que possamos entender quais são esses dispositivos de poder que agem sobre as vivências das personagens envolvidas na trama de modo a regularem suas sexualidades no que tange a uma espacialidade rural (Samambaia) e uma espacialidade urbana (Rio de Janeiro).

Principalmente mediante as contribuições de Foucault (1988), por meio de História da Sexualidade, concebemos que conhecimento e sexo se tornaram conceitos inseparáveis. Segundo Sedgwick (2007, p. 29), "de tal modo que conhecimento significa em primeiro lugar conhecimento sexual; ignorância, ignorância sexual". Dessa forma, ao ficar evidente, no século XIX, que conhecimento significava conhecimento sexual, segredos, segredos sexuais, "o efeito gradualmente reificante dessa recusa significou que se havia desenvolvido, de fato, uma sexualidade particular, distintivamente constituída como segredo" (SEGDWICK, 2007, p. 30).

Nessa perspectiva do segredo e, consequentemente, de sua possível ligação com a temática do armário, e ainda caminhando com as contribuições de Miskolci (2007, p. 58), em seus comentários a respeito da obra de Sedwick (2007), o autor explicita que:

O armário é uma forma de regulação da vida social de pessoas que se relacionam com outras do mesmo sexo, mas temem as consequências nas esferas familiar e pública. Ele se baseia no segredo, na "mentira" e na vida dupla. Esta tríade constitui mecanismos de proteção que também aprisionam e legam consequências psíquicas e sociais àqueles que nele se escondem. 
Dividir-se em dois, manter uma fachada ilusória entre si mesmo e aqueles com quem convive, exige muito esforço e capacidade para suportar o medo de ser descoberto. O temor cria a necessidade de estar sempre alerta para sinais que denunciem sua intimidade e desejos, evitar lugares e pessoas que o associem a uma identidade temida, força para agir contra seus próprios sentimentos e manter o compromisso com a ordem social que o rejeita, controla e poda das mais variadas formas.

O temor e as consequências da possibilidade de vivência das sexualidades, no espaço público e familiar, é visivelmente proferida por Mary no diálogo descrito anteriormente, ao dizer que "somos discretas no Rio", ou de como o pertencimento à Samambaia atenua o sentimento de rechaçamento social ou de distanciamento geográfico. Assim, precisamos também pensar na configuração do pertencimento a um momento frágil na história brasileira, como a década de 60 , e principalmente com as proximidades do Golpe Militar em 1964, ao refletir sobre as regulações e, de como o armário era conveniente nesse cenário, visto as possíveis represálias advindas de uma vida fora dele.

O filme em si não retrata a vivência decorrente de possíveis atos discriminatórios contra a lesbianidade das personagens, a não ser por esse diálogo entre Mary e Bishop, o que nos deixa instigadas e instigados, tendo em vista as problemáticas dos relacionamentos afetivo-sexuais entre sujeitos LGBTTTQI+ nessa década. Vemos, nas cenas que compõe o filme, que o círculo social das personagens é bem restrito, composto por amigas e amigos que compartilham de seus segredos, ou seja, as relações ainda ficam exclusivas ao micro espaço criado para um possível conforto de suas vivências eróticas e afetivas.

Ainda de acordo com Miskolci (2007, p. 59), ter uma vivência na perspectiva do armário é uma experiência marcante na produção das subjetividades daquelas/es que vivem suas vidas baseadas nos desejos secretos ou estão aprisionadas/os a exercerem sua sexualidade somente no espaço do privado.

Estes homens e estas mulheres, evitando a rejeição familiar e social, contribuem para manter suas instituições e valores. É difícil precisar, mas impossível ignorar, como as famílias se mantêm unidas e como o espaço público parece tão esmagadoramente heterossexual graças a este dispositivo, no qual a vontade individual se mescla à contribuição para o próprio assujeitamento e subordinação (MISKOLCI, 2007, p. 59).

A contribuição para a permanência das instituições de uma ordem estritamente heterossexual é algumas vezes apresentada na narrativa fílmica de Flores Raras. Isso ocorre principalmente no modelo de estruturação das personagens no que se refere à construção de um modelo heterocentrado a uma dicotomia normativa que é claramente visualizada na cena 'Chegada ao Brasil', no modo das vestimentas, no comportamento e 
também em uma construção das diferenças, muitas vezes, polarizada entre Lota e as demais mulheres Mary e Bishop.

A teoria do armário foi criada por Sedgwick, pensando no contexto americano e sob forte influência do modo de vida dos movimentos sociais presentes em determinada época, como por exemplo, os eventos de junho de 1969, mediante as revoltas de Stonewall. Dessa forma, é importante compreendermos também como ele se efetiva no nosso sistema brasileiro, que diferente do americano foi pouco marcado por revoluções de movimentos LGBTTTQI+. Miskolci (2007, p. 61) ainda complementa dizendo que: "a porta do armário parece maior no Brasil, onde vigoram conflitos acirrados de uma sociedade altamente desigual em todos os aspectos, inclusive na sexualidade".

Outro aspecto a ser ressaltado quando trazemos a obra de Sedgwick (2007) para essa escrita, na tentativa de entrelaçar com o filme, é a de que não estamos querendo trazer à tona a concepção da saída do armário, mesmo que ela seja problematizada diversas vezes em sua obra. Mas, de antemão, tentar entender os mecanismos do armário enquanto espacialidade, que nesse caso foi constituída como Samambaia. Ao analisarmos Flores Raras, constatamos que, mesmo em uma época de opressão, a preocupação da narrativa passa longe das perspectivas de uma fobia, e nesse caso uma lesbofobia. O único momento que observamos uma provável saída do armário é na cena 'Chegada ao Brasil', mas que não ocupa sequer um fragmento considerável na história que a trama tende a traçar.

\section{Cena: Heterotopias, imaginário das águas e dos cabelos}

O filme explode entrelaçando a simbologia das águas e dos cabelos em cenas eróticas.

Chevalier e Gheerbrant (1998) apresentam o verbete 'cabelo': "pentear os cabelos de alguém é um sinal de atenção, de boa acolhida; deixar-se pentear por alguém é sinal de amor, de confiança, de intimidade. Pentear alguém longamente significa embalar, adormecer ou acariciar esse alguém" (ibidem, p. 155). E pentear alguém nas águas do banho? Remete à intimidade, ao vínculo, ao erotismo. Há cenas belíssimas tanto entre Mary e Lota, quanto entre Lota e Bishop. Com relação a isso, Chevalier e Gheerbrant comentam que "a virtude purificadora e regeneradora do banho é bem conhecida e atestada, tanto no âmbito do profano como no do sagrado" (ibidem, p. 119).

A banheira na qual as amantes mergulhavam em erotismo constituía-se em outro espaço, em uma heterotopia. A expressão da personagem, tão bem captada pelas câmeras da filmagem, refletia calma, segurança, ternura, prazer (Figura 3). "A imersão, 
voluntariamente consentida e que é uma espécie de enterramento, é a aceitação de um momento de esquecimento, de renúncia à sua própria responsabilidade, um 'colocar-se fora do jogo', uma espécie de vacuidade" (ibidem, p. 119). A personagem, decidida e controladora, que gerenciava o sítio denominado Samambaia - os funcionários, as construções edificadas, os jardins -, tinha seu momento de entrega nas águas daquela banheira.

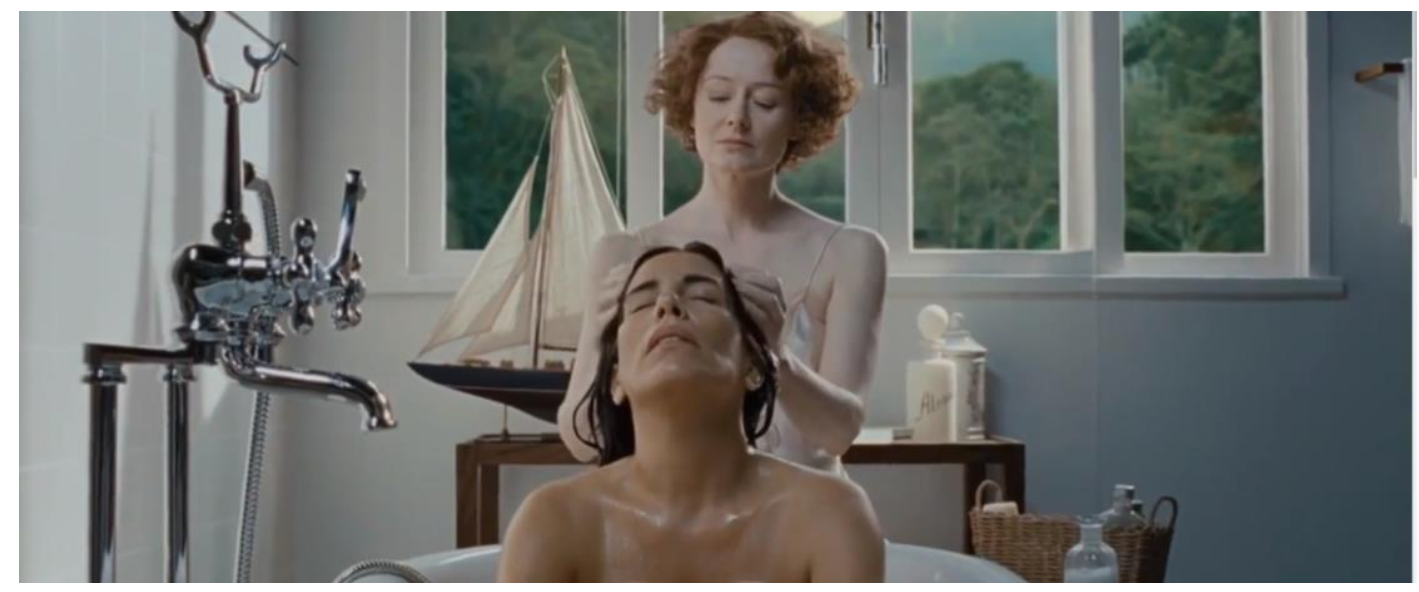

Figura 3: O banho

Fonte: Flores Raras, 2013

Assim como a banheira, a vida em Samambaia é um espaço heterotópico, ou, conforme Foucault (2013), de contraespaços, ou seja, "lugares que se opõe a todos os outros, destinados, de certo modo, apagá-los, neutralizá-los ou purificá-los" (FOUCAULT, 2013 , p. 20). O roteiro se baseia tanto nessa ideia de uma concepção de purificação, ou de sobrepor os espaços do público e do privado, que tornam a espacialidade de Samambaia quase que um terreno purificado. Perde-se nesse momento, portanto, uma forma de impossibilitar uma vivência e uma visibilidade lésbica fora dos arredores dessa redoma de proteção.

Ainda refletindo sobre as questões da heterotopia, na segunda parte do livro $O$ corpo utópico, as Heterotopias, Foucault (2013) nos apresenta o conceito de heterotopia, pensando talvez em uma conceituação para um espaço real, para tentar diferenciá-lo das utopias, que teoricamente são consideradas espaços irreais, imaginários, aquilo que não tem lugar algum. Nesse sentido, propõe cinco princípios para poder dar um sentido a essa palavra, explicando também alguns tipos de heterotopias que nos são apresentadas cotidianamente.

Reportamo-nos a esse conceito para pensar, assim como na epistemologia do armário, alguns fragmentos que compõem a espacialidade e o uso do privado para a construção dos corpos das personagens envolvidas, bem como o que esse espaço tem 
afetado na efetivação de uma vivência lésbica por parte da narrativa. Assim, como bem definido por Foucault, estamos pensando no espaço real, no espaço da concretude, um contraespaço, que de uma forma ou de outra tende a apagar outros espaços, como no caso de Flores Raras, o quase apagamento da construção de um corpo lésbico fora de Samambaia.

Como já dito anteriormente, o primeiro termo a ser apresentado seria o de contraespaços, ou seja, "lugares que se opõe a todos os outros, destinados, de certo modo a apagá-los, neutralizá-los ou purificá-los" (FOUCAULT, 2013, p. 20). O autor cita esses outros espaços, como o fundo do jardim, o celeiro ou até mesmo a cama ${ }^{8}$ dos pais e das mães e, nesse caso, Samambaia.

Para Foucault (2013), esses espaços são criações dos sujeitos. A sociedade adulta organizou seus próprios contraespaços (os jardins, os zoológicos, os teatros, as bibliotecas, as salas de cinema, as prisões, os cemitérios, museus, parques, entre outros), "esses lugares reais fora de todos os lugares" (FOUCAULT, 2013, p. 20).

Uma caixa poderia constituir-se em contraespaço? Por que essa pergunta? A relação íntima que possibilitava os cabelos de Lota e suas amantes, primeiro Mary e depois e, principalmente, Elizabeth, fez com que a personagem, quando estava internada em um hospital psiquiátrico, cortasse seus cabelos e os colocasse em uma caixa para ser enviado ao seu amor. As mechas de cabelos significam, para muitas pessoas, "mais do que o simples desejo de perpetuar uma recordação: elas revelam quase uma vontade de fazer sobreviver o estado da pessoa a quem esses cabelos pertenciam" (CHEVALIER e GHEERBRANT, 1998, p. 153). Assim, uma caixa contendo uma mecha de cabelos se tornou um contraespaço: lugar de denunciar vínculos.

Em 1996, Foucault sonhou com uma ciência que estudaria esses espaços, esses espaços diferentes, esses outros lugares, essas refutações do fantástico e real no espaço em que estamos inseridos. Essa ciência poderia estudar as heterotopias e chamaria 'heterotopologia'. Voltando à perspectiva teórica do autor, quando ele escreve o texto $O$ corpo utópico, as heterotopias, dá a nós indícios de alguns princípios que essa ciência deve possuir, ao todo cinco. No decorrer da escrita, tentaremos explorá-los.

No princípio, Foucault afirma que toda sociedade constitui sua heterotopia ou suas heterotopias e que elas se divergem de lugares para lugares, de culturas para culturas, ou seja, não há uma forma linear que se mantém constante. O autor dá alguns exemplos, como as sociedades primitivas com seus lugares privilegiados, sagrados ou

\footnotetext{
${ }^{8}$ É nessa grande cama que se descobre o oceano, pois nela se pode nadar entre as cobertas; depois, a grande cama é também céu, porque se pode saltar sobre as molas; é a floresta, pois se pode se esconder nela; é a noite, porque ali se pode virar um fantasma entre os lençóis; é enfim, o prazer, pois no retorno dos pais, serse-á punido (FOUCAULT, 2013, p. 20).
} 
proibidos. Nós nos debruçamos, a seguir, mais uma vez, na simbologia da lua, navegando por algumas culturas que são reveladoras em Flores Raras.

Chevalier e Gheerbrant afirmam que, no Yin e Yang - princípios da filosofia chinesa -, "a lua é Yin em relação ao Sol Yang: ela é passiva, receptiva. Ela é a água em relação ao fogo solar. Passiva e produtora da água, ela é fonte e símbolo de fecundidade" (CHEVALIER e GHEERBRANT, 1998, p. 562). Na Samambaia heterotópica lua e água embebiam a espacialidade com seus imaginários. Entre os astecas, as divindades lunares compreendiam os deuses da embriaguez. Não têm fim os fios que podem ser puxados na trama do filme problematizado. Muitos brindes, no desenrolar das cenas, e a personagem Elizabeth constantemente se embriagando. Sempre com uma taça na mão, inspirando-se para a escrita. Os autores comentam que "a embriaguez, ligada à fecundidade, às searas, à riqueza das colheitas, tem muito a ver com os fenômenos lunares" (ibidem. p. 364). Nas tradições de origem semítica, o vinho é o símbolo do conhecimento. No filme, a bebida encharcava os momentos da produção poética, mas também inundava a embriaguez de amar, o desejo das personagens em viverem intensamente, naquele espaço heterotópico, a enchente das expressões de prazer.

Mergulhemos no segundo, terceiro e quarto princípios: toda sociedade pode perfeitamente desfazer o acontecimento de uma heterotopia, ou organizar uma que ainda não existia. Um exemplo seriam as casas de prostituição na Europa, onde houve um maçante movimento para o seu desaparecimento. Outro exemplo seriam os cemitérios, que anteriormente não tinham a mesma significação que tem atualmente. Para Foucault (2013, p. 24), "a heterotopia, tem como regra justapor em um lugar real vários espaços que, normalmente, seriam ou deveriam ser incompatíveis". Durante o texto, menciona diversas heterotopias: teatro, cinema, jardim. Ele ainda conceitua com subdivisões: heterotopias do tempo (museus, bibliotecas) próprias à nossa cultura, heterotopias não eternitárias (teatro, as feiras, colônias de férias), heterotopias de festa.

Desafiamo-nos a problematizar os jardins de Flores Raras. Lota se inspirou em Samambaia para idealizar o parque urbano público Aterro do Flamengo? Samambaia era espaço privado, o seu armário. O jardim no Rio de Janeiro, por sua, público. Sua ideia era a de um parque que pudesse interferir na melhoria da qualidade de vida dos/das cariocas. Assim, a arquiteta autodidata Maria Carlota Costallat de Macedo Soares não queria um parque convencional, com fontes, bancos, bustos de celebridades e parquinhos. Se o parque não fosse repleto de equipamentos, os espaços sugeririam a sensação de liberdade. Tanto em Samambaia quanto no Parque do Flamengo, os espaços eram para vivências paradisíacas. Diferentes em suas particularidades - do privado em Samambaia e do público no Parque do Flamengo, emergem, em ambos espaços, as relações de poder - a natureza domesticada. Chevalier e Gheerbrant (1998) dizem que 
"o jardim é um símbolo de cultura por oposição à natureza selvagem, de reflexão por oposição à espontaneidade, da ordem por oposição à desordem, da consciência por oposição ao inconsciente" (CHEVALIER e GHEERBRANT, 1998, p. 513). Se a heterotopia justapõe, em um lugar real, vários espaços que seriam incompatíveis, então, público e privado são dicotomias que não cabem nesta análise. Cabe frescor, sombra, refúgio e liberdade!

Finalmente, o quinto princípio, segundo Foucault (2013, p. 26): "as heterotopias possuem sempre um sistema de abertura e de fechamento que as isola em relação ao espaço circundante". A heterotopia "é um livro aberto, que tem, contudo, a propriedade de nos manter de fora". O filósofo cita exemplos como as casas do século XVIII, nas quais havia um pequeno aposento exterior a casa. Qualquer pessoa poderia fazer uso do local, entretanto, esse aposento não possibilitava, de modo algum, a entrada para o restante da casa: "Esse aposento era uma espécie de heterotopia inteiramente exterior". As heterotopias, nesse sentido, são contestações que podem ser exercidas.

Assim, o quinto ponto descrito por Foucault se enlaça na questão da territorialidade ou de como queremos entender uma construção da narrativa, quando pensamos nas personagens envolvidas em Samambaia. Atentemos, principalmente, para as duas citações "as heterotopias possuem sempre um sistema de abertura e de fechamento que as isola em relação ao espaço circundante" e "é um livro aberto, que tem, contudo, a propriedade de nos manter de fora". Essas compreensões casam com o que já discutimos anteriormente, quando também pensamos na perspectiva do armário, na medida em que consideramos um fechamento ou abertura do espaço circundante e na propriedade de nos manter de fora.

Pensamos na possibilidade de alinhar os dois conceitos trazidos justamente para elencar essa contradivisão espacial criada na narrativa fílmica, como o espaço do privado e do público, ou de como esse corpo heterotópico se apropria das heterotopias criadas para a produção de suas subjetividades. Objetivando, dessa forma, cenas como os beijos nos arredores de Samambaia, os momentos de afetividade e erotismos concretizados, a produção artística de Bishop, dentre outros.

Por fim, o que gostaríamos de provocar ou de problematizar é de fato, a partir desses pontos elencados, a reflexão sobre a produção desses corpos, dessas subjetivações nesse espaço heterotópico, e de como a narrativa fílmica possibilita, por meio desse espaço efetivado, um corpo diferente dos subjetivados em outros espaços, como por exemplo, em uma contraposição entre Samambaia e Rio de Janeiro. Devemos atentar que as heterotopias sãos lugares de passagens e que Samambaia se constitui como um lugar de transitoriedade. 


\section{Subjetivações sem fim}

As inquietações, as dúvidas e as possibilidades de novas análises, a partir de outros olhares, são convites necessários para pensar o cinema lésbico brasileiro e a produtividade de suas narrativas, de seus aspectos técnicos, das personagens que são envolvidas pela trama, das relações que se pode fazer por meio dos modos de endereçamento que recaem sobre nós telespectadores/as.

De fato, mesmo que não tenhamos analisado todos esses componentes que se encontram no filme Flores Raras, compreendemos que são de grande importância para o processo de subjetivação por meio de seus elementos: montagem, som, narrativa, dentre outros, tornando dessa forma, passíveis de problematização e análises.

Levando em consideração essa perspectiva do não encerramento, da não finitude, da não conclusão aliada às análises e problematizações realizadas, conseguimos adentrar em determinados territórios para pensar a mulher lésbica frente às imagens, por meio de eixos temáticos, tais como corpo, sexualidades, espacialidades, geografias, heterotopias, simbologias e o imaginário das águas.

Problematizamos as visibilidades possíveis, quando pensamos nessas mulheres lésbicas retratadas por intermédio das imagens, de como os/as diretores/as e de como as narrativas compõem determinados meandros na tentativa de um entendimento sobre o imaginário que recai sobre esses sujeitos presentes nas materialidades fílmicas.

Constituiu-se um grande desafio problematizar os saberes e as verdades que são estabelecidos a partir do cinema brasileiro sobre o corpo lésbico, sobre suas vivências e sobre as espacialidades que ocupam. Este artigo não decretou verdades e o objetivo desta pesquisa/escrita foi respeitar e considerar as lesbianidades em suas mais variadas e diversas formas.

Outra justificativa, que se ancora na perspectiva retratada, está atrelada muito mais a uma crítica e a uma análise a partir das cenas e, consequentemente, o que os/as diretores/as pensam sobre a perspectiva das lesbianidades, do que uma inferência generalizada a partir de pressupostos enquanto pesquisadores/as. A potencialidade dos modos de endereçamento justifica ainda mais essa cautela, pois, a partir dos processos de subjetivação que recaem sobre nós, foi possível um processo analítico sobre essas imagens.

Dessa forma, gostaríamos de salientar que a intencionalidade não foi ocupar o espaço de fala das mulheres e, fundamentalmente, das mulheres lésbicas sobre seus corpos, seus desejos, sobre sua sexualidade. Mas sim, entender os meandros 
circunscritos a partir das narrativas e da composição das personagens presentes no filme selecionado. O trabalho aqui sobre as lesbianidades serve como proposta de colaboração, de problematização e de desmistificação.

\section{Referências}

AUGRAS, M. Imaginário da magia: magia do imaginário. Petrópolis, RJ: Vozes; Rio de Janeiro: Editora PUC. 2009.

ANASTÁCIO, S. M. G. Momentos brasileiros no processo de criação de Elizabeth Bishop. Revista SOLETRAS, n. 3, p. 65-74, 2002.

CHEVAlier, J. e G., A. Dicionário de Símbolos. Mitos, sonhos, costumes, gestos, formas, figuras, cores, números. 12. ed. Rio de Janeiro: José Olympio, 1998.

DURAND, G. As estruturas antropológicas do imaginário. Introdução à arquetipologia geral. Tradução de Helder Godinho. São Paulo: Martins Fontes, 1997.

ELLSWORTH, E. Modos de endereçamento: uma coisa de cinema; uma coisa de educação também. In: SILVA, T. T. da (org.). Nunca fomos humanos: nos rastros do sujeito. Belo Horizonte: Autêntica, 2001. p. 7-76.

FOUCAULT, M. O corpo utópico, as heterotopias. São Paulo: n-1 edições, 2013.

História da Sexualidade I: A Vontade de Saber. Rio de Janeiro: Graal, 1988.

FLORES Raras. Direção de Bruno Barreto. Produção de Paula Barreto e Lucy Barreto. Barueri: Imagem Filmes/20th Century Fox, 2013. 1 DVD (118 minutos), Ntsc, son., color.

MIGLIORIN, C; BARROSO, E. I. Pedagogias do cinema: montagem. Significação: Revista de Cultura Audiovisual, v. 44, n. 46, p. 15-28, 2016.

MISKOLCI, R. Machos e "Brothers": uma etnografia sobre o armário em relações homoeróticas masculinas criadas on-line. Estudos Feministas, p. 301-324, 2013.

Comentário. Cadernos Pagu, n. 28, p. 55-63, 2007.

PEREIRA, O. A. A. Flores raras: banquete de imagens e poesia. Ângulo, n. 138, p. 42$53,2015$.

PRECIADO, P. B. Cartografias queer: o flâneur perverso, a lésbica topofóbica e a puta multicartográfica, ou como fazer uma cartografia "zorra" com annie sprinkle. Inhumas, ano 5, n. 17, jan. p. 1-32, 2017.

SEDGWICK, E. K. A epistemologia do armário. Cadernos Pagu, v. 28, n. 1, p. 19-54, 2007.

' Doutorado em Educação (UFSCar). Professor substituto no Departamento de Educação da Universidade Federal de Lavras (UFLA/MG).

ii Professora Titular Aposentada do Departamento de Educação da Universidade Federal de Lavras (UFLA/ MG).

iii Doutor em Educação (Unicamp). Professor Titular no Departamento de Educação e no Programa de Pós-Graduação em Educação da Universidade Federal de São Carlos (UFSCar/SP). 
Como citar esse artigo:

PAULINO, Alessandro Garcia; RIBEIRO, Cláudia Maria; DINIS, Nilson Fernandes. Flores Raras: lesbianidades e as espacialidades de armários e heterotopias. Revista Digital do LAV, Santa Maria: UFSM, v. 13, n. 2, p. 274-290, mai./ago. 2020. 